\title{
Seasonality in Agricultural Commodity Futures
}

\author{
Carsten Sørensen* \\ Department of Finance \\ Copenhagen Business School \\ Rosenørns Allé 31 \\ DK-1970 Frederiksberg \\ Denmark \\ TEL: +4538153615 \\ FAX: +4538153600 \\ E-mail: cso.fi@cbs.dk
}

December 1999

* The author thanks for helpful assistance from Jesper Bülow and comments and suggestions from Johannes Mouritsen and seminar participants at Sørup Herregård and a lunch bag seminar at Copenhagen Business School. Financial support from the Danish Natural Science and Social Science Research Councils is gratefully acknowledged. 


\title{
Seasonality in Agricultural Commodity Futures
}

\begin{abstract}
The stochastic behavior of agricultural commodity prices is investigated using observations of the term structures of futures prices over time. The continuous time dynamics of (log-) commodity prices are modeled as a sum of a deterministic seasonal component, a non-stationary state-variable, and a stationary state-variable. Futures prices are established by standard no-arbitrage arguments and the Kalman filter methodology is used to estimate the model parameters for corn futures, soybean futures, and wheat futures based on weekly data from the Chicago Board of Trade for the period 1972-1997. Furthermore, in a discussion of the estimated seasonal patterns in agricultural commodity prices, we provide empirical evidence on the theory of storage that predicts a negative relationship between stocks of inventory and convenience yields; in particular, convenience yields used in this analysis are extracted using the Kalman filter.
\end{abstract}




\section{Introduction}

Inference about seasonality in commodity prices can be based on the time-series characteristics of sampled spot price observations. However, if the commodities are traded in a futures market, the forms taken by the term structure of futures prices provide separat information about seasonality in commodity prices. Consider for example futures prices for corn at the Chicago Board of Trade (CBOT): at a given date the corn futures prices will usually be higher for delivery in May and July than for delivery in March, September, or December. In this paper we provide a framework that is simultaneously able to explore the information about seasonality in the time-series as well as the panel-data characteristics of agricultural futures prices. The modeling framework and the empirical analysis focus on estimating the seasonal price patterns for corn, soybeans, and wheat.

The dynamics of the (log-) commodity spot price are in this paper modeled as the sum of a deterministic seasonal component, a non-stationary state-variable, and a stationary statevariable. The methodology used in the analysis is inspired by the continuous-time approach in Schwartz (1997) and, besides the seasonal component, the model is similar to the model suggested by Schwartz and Smith (1997). The deterministic seasonal component is modeled by a parameterized linear combination of trigonometric functions with seasonal frequencies. The non-stationary state-variable is modeled by the logarithm of a geometric diffusion process, well-known from the standard Black-Scholes setting, and is included in order to describe permanent price changes due to for example technology improvements, permanent changes in demand/taste, and general price increases due to common inflation. The stationary statevariable is modeled by an Ornstein-Uhlenbeck process and is included in order to model commodity price effects due to temporary periods of excess supply or demand and, hence, is meant to capture the mean reverting feature of commodity prices that has been pointed out by Gibson and Schwartz (1990, 1991), Brennan (1991), Cortazar and Schwartz (1994), Bessembinder, Coughenour, Seguin, and Smoller (1995), Schwartz (1997), and Schwartz and Smith (1997) among others. The inclusion of a stationary state-variable is also consistent with the so-called "Samuelson hypothesis" (Samuelson, 1965) that the volatilities of commod-

ity futures prices decrease with the contract horizon; this is pointed out by Bessembinder, Coughenour, Seguin, and Smoller (1996) who also present empirical evidence supporting the "Samuelson hypothesis" in the case of agricultural commodities. The "Samuelson hypothesis" is also confirmed by a casual investigation of the data used in the empirical analysis in 
this paper (summary statistics are provided and discussed in section 3), and this observation is part of the motivation for the specific construction of the seasonal two-factor model.

Following the no-arbitrage approach in Schwartz (1997), futures prices are determined by taking expectations of the future spot prices under an equivalent martingale measure (or, equivalently, by solving a particular partial differential equation). When establishing the dynamics of the basic state-variables under the equivalent martingale measure, it is assumed that risk premia are constant. In the present model, (log-) futures prices are affine functions of the two stochastic state-variables. This fact, combined with the specific assumptions on the dynamics of state-variables, makes maximum likelihood estimation possible. The approach is based on a state space formulation of the problem and an application of the Kalman filter in a prediction error decomposition of the log-likelihood function. We use weekly futures data based on settlement prices from CBOT in the period from January 1972 to July 1997 to estimate the parameters for corn, soybeans, and wheat.

The estimated seasonal price components in the agricultural commodity futures prices peak two to three months prior to the harvesting periods and reach their bottoms after the harvesting periods. The price patterns are consistent with the reasoning that, in order to have demand equal supply, periods of low levels of supply (i.e. before the harvesting periods) are also periods with relatively high commodity prices whereas periods with plenty supply (i.e. after the harvesting periods) are periods with relatively low commodity prices.

The possibilities of storage imply that excess supplies can be carried over to future periods, and another perspective on the seasonal patterns inherent in the agricultural futures prices can be gained by applying the basic ideas from the theory of storage by Kaldor (1939), Working (1948, 1949), Brennan (1958), and Telser (1958). The theory of storage explains the differences between the spot and futures prices with different contract horizons in terms of advantages of physical inventory compared to advantages of ownership of a futures contract for future delivery of the commodity. Physical inventory is associated with cost of carry such as storage costs and the interest forgone by investing in storage. On the other hand, physical inventory gives rise to a convenience yield from being able to profit from temporary price increases due to temporary shortages of the particular commodity or from being able to maintain a production process despite abrupt shortages of the commodity used as input. More generally, the convenience yield on a commodity can be defined as the flow of services which accrues to the owner of physical inventory but not to the owner of a contract for future delivery; see e.g. Brennan (1991). 
Kaldor (1939) and Working $(1948,1949)$ both expected the convenience yield to depend inversely on the stocks of inventory of the commodity; as in Brennan (1991), we will refer to this negative relationship between inventories and convenience yields as the Kaldor-Working hypothesis. In fact, Working $(1948,1949)$ originally pointed out that this could explain the phenomenon of contango, understood in this context as a negative basis (i.e. futures price minus spot price), in agricultural commodities just before the harvesting seasons where inventories are at their lowest and convenience yields thus at their highest. ${ }^{1}$ This observation and explanation is also consistent with the seasonal price patterns estimated in this paper. The seasonal price patterns suggest that commodity prices tend to peak prior to the harvesting periods. Through the harvesting periods the spot commodity prices are expected to fall and, basically, the marginal investors carrying inventories must experience relatively high expected returns in the form of convenience yields in order to break even in these periods. After the harvesting periods convenience yields are low and the estimated seasonal price patterns suggest that spot commodity prices tend to increase. This is consistent with the observation that the marginal investors carrying inventories must somehow be compensated for the costs of carry and in this case by expected returns in the form of spot commodity price increases.

Taking as a fact of life that inventories for commodities like corn, soybeans, and wheat display seasonal patterns due to their production cycles, the theory of storage (combined with the Kaldor-Working hypothesis) predicts that convenience yields must display seasonal variation. Using this insight, Fama and French (1987) provide empirical evidence on the theory of storage by showing that convenience yields $d o$ vary seasonally for most agricultural and animal products but not for metals.

In our modeling framework, the seasonal component is an important ingredient in the determination of implied convenience yields but it only explains part of the convenience yield at any given date. In fact, convenience yields implied by the model will be shown to be only a function of the stationary state-variable $z_{t}$, as well as time; moreover, the convenience yield is an affine function of $z_{t}^{2}$ and can thus be estimated appropriately using

\footnotetext{
${ }^{1}$ The use of the concept contango, in this context, is not entirely consistent with the usual definition of contango as the situation where the futures price is above the expected future spot price (see e.g. Hull (2000), p. 74). Normal backwardation is the opposite case. Since the futures price can be viewed as the expected future spot price under the equivalent martingale measure, only risk premia matter for whether contango or normal backwardation is the case. The estimates obtained in this paper suggest that normal backwardation is the case for soybeans and wheat while the results for corn are mixed, as discussed in section 4 .

${ }^{2}$ Likewise, Schwartz and Smith (1997) demonstrate equivalence of their non-seasonal counterpart of the
} 
the Kalman filter within our modeling framework. As an implication, this for example implies that if the term structure of futures prices moves from being increasing to being decreasing in the contract maturity, or vice versa, this cannot in general be attributed entirely to a change in season but will typically also be a consequence of a change in the stationary state-variable $z_{t}$ which captures price effects due to periods of temporary excess supply or demand unrelated to seasonal aspects. Using the Kalman filtered convenience yields and inventory data, we present empirical evidence in line with the theory of storage and the Kaldor-Working hypothesis that predicts a negative relationship between stocks of inventory and convenience yields. This analysis is analogues to the empirical analyses in Brennan (1958) and Telser (1958) and, in particular, similar to the analysis in Brennan (1991) since we apply the same non-linear structural form when regressing estimated convenience yields on stocks of inventory. As a conceptual improvement compared to Brennan (1991), the estimation of convenience yields by the Kalman filtering approach in this paper takes into account the seasonal variation in convenience yields, which is of particular importance for the involved agricultural commodities in the this study.

The explicit modeling of commodity and futures price dynamics, as in this paper, is relevant and applicable for hedging contracts for future delivery. This issue is discussed extensively in Schwartz (1997) and many of the points can be directly carried over to our setting; ${ }^{3}$ in fact, the Black-Scholes pricing formula for European options derived in Schwartz and Smith (1997) can be shown to be valid in our setting as well because the models only differ by a deterministic seasonal component. Although the seasonal model of agricultural commodity futures dynamics has potential use in this context, we have no conceptual contributions to this discussion and, therefore, will not pursue this line of research.

The paper is organized as follows. The basic model and the state space estimation approach are described in section 2 and section 3 presents the data. The estimation results are presented and discussed in section 4 where the precise construction and estimation of convenience yields used in the empirical analysis of the Kaldor-Working hypothesis is also

two-factor model in this paper and the Gibson and Schwartz (1990) model in the sense that in both models convenience yields are affine functions of a mean-reverting Ornstein-Uhlenbeck process.

${ }^{3}$ See also Brennan and Schwartz (1985), Gibson and Schwartz (1990), Jamshidian and Fein (1990), Bjerksund (1991), Cortazar and Schwartz (1994), Dixit and Pindyck (1994), Schwartz and Smith (1997), Hilliard and Reis (1998), and Miltersen and Schwartz (1998) for advances on no-arbitrage models with a focus on the valuation of commodity contingent claims, such as real options, and hedging. 
provided. Section 5 concludes.

\section{The model and estimation methodology}

In this section we will present the basic model of agricultural commodity price dynamics, derive the relevant formulas for the pricing of futures contracts, and describe the estimation approach that will be used in the empirical analysis.

\subsection{Commodity price dynamics}

The logarithm of the commodity spot price $p_{t}=\log P_{t}$ is modeled as the sum of a deterministic seasonal component described by a function of time only and two state-variables $x_{t}$ and $z_{t}$. Formally, we assume that

$$
p_{t}=s(t)+x_{t}+z_{t}
$$

where

$$
s(t)=\sum_{k=1}^{K}\left(\gamma_{k} \cos (2 \pi k t)+\gamma_{k}^{*} \sin (2 \pi k t)\right)
$$

with $K$ determining the number of terms in the sum and $\gamma_{k}, \gamma_{k}^{*}, k=1, \ldots, K$, being constant parameters to be estimated. Time is measured in years and, hence, the first term in the sum repeats itself with a yearly frequency; the second term has a half-yearly frequency and so on. The specific form of the seasonal component was suggested by Hannan, Terrell and Tuckwell (1970) as an alternative to standard dummy variable methods of modeling seasonality. This way of modeling seasonality is chosen because it eases the flexibility of dealing with time in the determination and handling of futures term structures in the empirical analysis.

The dynamics of $x_{t}$ and $z_{t}$ are described by a system of differential equations on the form:

$$
\begin{gathered}
d x_{t}=\left(\mu-\frac{1}{2} \sigma^{2}\right) d t+\sigma d W_{1 t} \\
d z_{t}=-\kappa z_{t} d t+v d W_{2 t}
\end{gathered}
$$

The Wiener processes $W_{1 t}$ and $W_{2 t}$ are assumed correlated with constant correlation coefficient $\rho$, and it is assumed that the standard filtration generated by the two-dimensional Wiener-process $\left(W_{1 t}, W_{2 t}\right)$ describes all the information available in the economy.

The state-variable $x_{t}$ follows a non-stationary Wiener process with constant drift and diffusion parameters, which can be thought of as the logarithm of a geometric diffusion process with constant drift rate $\mu$ and constant diffusion rate $\sigma$, as used to model asset price 
dynamics in the standard Black-Scholes option pricing set-up. The state-variable $z_{t}$ follows an Ornstein-Uhlenbeck process with constant parameters $\kappa$ and $v$; for $\kappa>0$ this is a stationary process.

The basic idea in the above modeling of intertemporal commodity price behavior is that $s(t)$ captures price movements that are entirely related to the season, the state-variable $x_{t}$ captures permanent price changes due to permanent changes in supply or demand while $z_{t}$ captures temporary price changes due to temporary changes in supply or demand. Besides the seasonal component the model is basically identical to the model suggested by Schwartz and Smith (1997). In the context of real exchange rates, Sørensen (1997) demonstrates that the above kind of commodity price behavior is consistent with equilibrium (and, hence, excludes arbitrage opportunities) in a two-good general equilibrium model where the interest rate may be constant or stochastic and risk premia are constant. ${ }^{4}$ In principle, the equilibrium model of Sørensen (1997) can be viewed as an analogue to the Cox, Ingersoll, and Ross (1985) model which is set up so as to support a specific no-arbitrage model of the term structure of interest rates. This puts the above modeling on solid ground and at least compatible with for example the no-arbitrage models in Schwartz (1997), Hilliard and Reis (1998), and Schwartz and Miltersen (1998). However, it is a potential drawback that the dynamic general equilibrium model in Sørensen (1997) is based on a pure-exchange economy and, hence, the commodity price dynamics are not derived as an equilibrium outcome of a model that incorporates intertemporal production, consumption, and especially inventory decisions by economic agents in a sense that captures the basic ideas in the theory of storage in a realistic and meaningful way. ${ }^{5}$

\section{$2.2 \quad$ Futures prices}

Under the so-called equivalent martingale measure, which is relevant for pricing and denoted here by $Q$, the dynamics of the two state-variables $x_{t}$ and $z_{t}$ are assumed described by

$$
\begin{gathered}
d x_{t}=\left(\alpha-\frac{1}{2} \sigma^{2}\right) d t+\sigma d W_{1 t}^{Q} \\
d z_{t}=-\left(\lambda_{z}+\kappa z_{t}\right) d t+v d W_{2 t}^{Q}
\end{gathered}
$$

\footnotetext{
${ }^{4}$ For the remaining analysis we will thus assume constant risk premia and not make any specific assumptions on the interest rate dynamics.

${ }^{5}$ For recent advances in the theory of asset price dynamics in the spirit of the ideas in the theory of storage; see e.g. Wright and Williams (1989), Williams and Wright (1991), Deaton and Laroque (1992, 1996), Chambers and Bailey (1996), Routledge, Seppi, and Spatt (1998, 1999).
} 
where $\alpha=\mu-\lambda_{x}$, and $\lambda_{x}, \lambda_{z}$ are constant market prices of risk associated with $x_{t}$ and $z_{t}$, respectively. Moreover, $W_{1 t}^{Q}$ and $W_{2 t}^{Q}$ describes the Wiener-processes under $Q$.

Cox, Ingersoll and Ross (1981) have shown that the futures price on a futures contract expiring at time $\tau, \tau \geq t$, can be determined by taking the expectations under $Q$ of the final settlement price (the spot price at time $\left.\tau, P_{\tau}=e^{s(\tau)+x_{\tau}+z_{\tau}}\right) .{ }^{6}$ Let $F_{t}(\tau)$ denote the futures price at time $t$ on a futures contract that expires at time $\tau$. By taking the relevant expectations,

$$
F_{t}(\tau)=\exp \left[s(\tau)+A(\tau-t)+x_{t}+z_{t} e^{-\kappa(\tau-t)}\right]
$$

where

$$
A(\tau-t)=\alpha(\tau-t)-\frac{\lambda_{z}-\rho \sigma v}{\kappa}\left(1-e^{-\kappa(\tau-t)}\right)+\frac{v^{2}}{4 \kappa}\left(1-e^{-2 \kappa(\tau-t)}\right)
$$

An important feature of the model is that log-futures prices are affine functions of the two state-variables $x_{t}$ and $z_{t}$; a fact that facilitates a standard state space formulation of the model.

\subsection{State space estimation approach}

An applicable method for maximum likelihood estimation of the above model is by stating the problem in state space form and by using the Kalman filter in an error prediction decomposition of the log-likelihood function. Harvey (1989) has an extensive description of estimation, testing, and model selection of models in state space form which is basically applied below.

The state space form consists of a transition equation and a measurement equation. The transition equation describes the stochastic evolvement of an unobserved vector of statevariables. In our case the unobserved state-variables are $x_{t}$ and $z_{t}$ and the transition equation is the discrete version of the system of equations (3) and (4). In general, the measurement equation relates the unobserved state-variables to a vector of observables. In our case, we observe term structures of futures prices at different dates and the measurement equation relates these observations to $x_{t}$ and $z_{t}$ through the relation established in (7). Below, we will state the formal form of the transition equation and the measurement equation used for our purposes.

The data is sampled at equidistante time points $t_{n}, n=1, \ldots, N$, and $\Delta=t_{n+1}-t_{n}$ denotes the distance between any two observation dates. Let $X_{n}=\left(x_{t_{n}}, z_{t_{n}}\right)^{\prime}$ denote the

\footnotetext{
${ }^{6}$ It is a well-known fact that, by an application of the Feynman-Kac formula, the futures price can equivalently be evaluated as the solution to a specific partial differential equation, see e.g. Duffie (1996).
} 
unobserved state-vector at time $t_{n}$. Formally, the transition equation has the following form: ${ }^{7}$

$$
X_{n+1}=a+A X_{n}+\eta_{n}
$$

where $\eta_{n}, n=1, \ldots, N$ are independently normally distributed with zero mean-vector and covariance matrix $\Sigma$ and where

$$
a=\left(\begin{array}{c}
\mu-\frac{1}{2} \sigma^{2} \\
0
\end{array}\right), A=\left(\begin{array}{cc}
1 & 0 \\
0 & e^{-\kappa \Delta}
\end{array}\right), \Sigma=\left(\begin{array}{cc}
\sigma^{2} \Delta & \frac{\rho \sigma v}{\kappa}\left(1-e^{-\kappa \Delta}\right) \\
\frac{\rho \sigma v}{\kappa}\left(1-e^{-\kappa \Delta}\right) & \frac{v^{2}}{2 \kappa}\left(1-e^{-2 \kappa \Delta}\right)
\end{array}\right)
$$

The measurement equation relates the unobserved state-variables to observations of futures prices through the established relation in (7). Let $f_{t}(\tau)=\log F_{t}(\tau)$ and note that the established relationship between $f_{t}(\tau)$ and the unobserved state-variables is linear and therefore fits into a standard state space form. Furthermore, let $Z_{n}=\left(f_{t_{n}}\left(\tau_{n}^{1}\right), \ldots, f_{t_{n}}\left(\tau_{n}^{M_{n}}\right)\right)$ denote the set of (log-) futures prices observed at time $t_{n}$ and with maturities $\tau_{n}^{1}, \ldots, \tau_{n}^{M_{n}}$. Note that we, in contrast to e.g. Schwartz (1997), allow the dimensionality of the measurement equation, $M_{n}$, to vary since the number of futures contracts traded and quoted is changing over time and over the relevant sample period. The measurement equation has the following form:

$$
Z_{n}=c_{n}+C_{n} X_{n}+\epsilon_{n}
$$

where $\epsilon_{n}, n=1, \ldots, N$ are independently normally distributed with zero mean-vector and covariance matrix $H_{n}$ and in our analysis

$$
c_{n}=\left(\begin{array}{c}
s\left(\tau_{n}^{1}\right)+A\left(\tau_{n}^{1}-t_{n}\right) \\
\vdots \\
s\left(\tau_{n}^{M_{n}}\right)+A\left(\tau_{n}^{M_{n}}-t_{n}\right)
\end{array}\right), C_{n}=\left(\begin{array}{cc}
1 & e^{-\kappa\left(\tau_{n}^{1}-t_{n}\right)} \\
\vdots & \vdots \\
1 & e^{-\kappa\left(\tau_{n}^{M n}-t_{n}\right)}
\end{array}\right), H_{n}=\sigma_{\epsilon}^{2} I_{n}
$$

where $I_{n}$ is the identity matrix with dimension following from the context. The term $\epsilon_{n}$ allows for noise in the sampling of data and the simple form of the covariance matrix $H$ (with only one parameter $\sigma_{\epsilon}$ ) is chosen mainly for the presentation of results in the next section. ${ }^{8}$

The estimation of a model in state space form by maximum likelihood is standard and described in e.g. Harvey (1989), Chapter 3. Let $Z_{n \mid n-1}$ denote the conditional expectations

\footnotetext{
${ }^{7}$ This follows from solving equations (3) and (4).

${ }^{8}$ We carried out estimations for more general structures of $H$ where the entries were specified as parameterized functions of the time to maturity for the observed futures contracts as well. The more advanced forms for $H$, however, did not effect substantially the results obtained.
} 
of $Z_{n}$ and let $F_{n}$ denote the conditional variance of $Z_{n}$ conditional on information available at time $t_{n-1}$. Then, $Z_{n \mid n-1}$ and $F_{n}$ can be obtained recursively by an application of the Kalman filter and the so-called prediction error decomposition of the log-likelihood function takes the form:

$$
l\left(Z_{1}, \ldots, Z_{N} ; \Psi\right)=l\left(Z_{1} ; \Psi\right)-\sum_{n=2}^{N} \frac{M_{n}}{2} \log 2 \pi-\frac{1}{2} \sum_{n=2}^{N} \log \left|F_{n}\right|-\frac{1}{2} \sum_{n=2}^{N} \omega_{n}^{\prime} F_{n}^{-1} \omega_{n}
$$

where $l\left(Z_{1} ; \Psi\right)$ is the unconditional log-likelihood function for $Z_{1}$ and $\omega_{n}=Z_{n}-Z_{n \mid n-1}$ is the $n$ 'th prediction error. $\Psi$ summarizes the set of parameters to be estimated by maximizing (10). In the construction of $l\left(Z_{1} ; \Psi\right)$ we have followed a standard approach for dealing with a stationary and non-stationary state-variable and assumed that $z_{t}$ is initially distributed according to its steady state distribution while the starting value of $x_{t}$ (i.e. $x_{1}$ ) is treated as an extra parameter to be estimated.

\section{Data}

The parameters of the above model are estimated separately for three different agricultural commodities. The dataset consists of weekly observations of futures prices on corn, soybean, and wheat from CBOT in the period January 1972 to July 1997. The futures prices involved are settlement prices at CBOT for Wednesdays (or Tuesday if Wednesday is unavailable). In fact, settlement prices are available on a daily basis but the weekly sampling frequency is chosen mainly to reduce problems due to microstructure issues such as for example daily price limits imposed by CBOT.

The futures for corn and wheat have five expiration months: March, May, July, September, and December. CBOT soybean futures have 7 expiration months: January, March, May, July, August, September, and November. At any particular date, more than (or less than) 5 (7) futures contracts on corn and wheat (soybean) may be traded since for example futures with expiration in July this year and next year may be traded simultaneously.

In the estimation approach we need the times to maturity for the different futures contracts at the different sample dates. The contractual terms at CBOT specify that physical delivery (in the form of an inventory receipt) may occur at any business day throughout the expiration month and, hence, that the last delivery day is the last business day of the month. However, the last trading day of the futures contract is the seventh business day preceding the last business day of the delivery month. Since the last trading day is the last day that a 
contract can in principle be closed at CBOT without physical delivery, we have chosen this day as the expiration date when constructing the times to maturity for the involved futures contracts in the estimations presented in the next section.

In this section, we will describe the basic features of the data by tabulating some summary statistics and by illustration of the time series behavior of the data over the sampling period. We will be brief in our discussion of the issues involved; the formal empirical analysis is discussed in the next section.

Table 1 provides summary statistics with respect to the involved futures contracts for corn and Table 2 and Table 3 provide similar summary statistics for soybean futures and wheat futures.

\section{[ INSERT TABLE 1, TABLE 2, AND TABLE 3 ABOUT HERE ]}

The tables state the mean and standard deviation of all the futures contracts in the dataset for the three different agricultural commodities. In addition, the tables provide summary statistics for the futures contracts categorized into expirations months as well as the time to maturity of the contracts. In the following the terminology 1. closest maturity is used as notation for the futures contract that has the shortest time to maturity at a given sample date; the 2. closest maturity represents the futures contract with the second shortest time to maturity, and so on.

The tables indicate at least two important and basic features of the agricultural commodity futures prices: (i) futures prices display a seasonal pattern and, (ii) the variations of long futures prices are lower than short futures prices.

The seasonal patterns are indicated by the mean futures prices for the different expiration months in Table 1, Table 2, and Table 3. For corn futures and soybean futures the mean futures prices have a peak in July and reach a bottom in December/November. For wheat futures the mean futures prices reach a peak in March and a bottom in July.

The lower variation of futures prices with a long time to maturity compared to futures prices with a short time to maturity is suggested by the different standard deviations for the futures prices grouped into their time to maturity in Table 1, Table 2, and Table 3. In all the tables the standard deviations are decreasing for increasing maturities. This pattern is consistent with the "Samuelson hypothesis" and persistent within all tables. Note, however, that the very small standard deviations for the longest maturities to some extent merely reflect that the data for these contracts are sampled only over short continuous time periods. 
Hence, it may only make sense to compare the maturities for which we have observations at all 1335 sample dates but, anyhow, the pattern is evident.

The time series aspects of the data are illustrated by Figure 1, Figure 2, and Figure 3.

\section{[ INSERT FIGURE 1, FIGURE 2, AND FIGURE 3 ABOUT HERE ]}

In the figures we have graphed the time-series for the 1. closest maturity and the time-series for the 4. closest (5. closest) maturity for corn futures and wheat futures (soybean futures); these represent the shortest maturity series and longest maturity series for which we have observations at each sample date. A visual inspection of the figures suggests that the time series for the 1. closest maturity is slightly more volatile than the 4 . closest (and 5. closest) maturity time series. Again, this is in line with the "Samuelson hypothesis" and a feature of the agricultural commodity prices which is captured in the formal modeling in section 2 by including a stationary state-variable besides the deterministic seasonal component.

Another feature of the data which is suggested by Table 1, Table 2, and Table 3 is a seasonal component in futures price volatilities. The standard deviations in the tables are thus lowest (highest) for the futures contracts which have the lowest (highest) mean levels, although this is not exactly true for soybean futures. ${ }^{9}$ In our formal modeling, the seasonal component affect the level of commodity prices through multiplication ${ }^{10}$ and, hence, in principle gives rise to a pattern as exhibited by the standard deviations of the absolute commodity futures price levels in the tables. Anyhow, modeling a seasonal in volatilities is an interesting topic for future research but outside the scope of this paper.

\section{Empirical results}

In this section the estimation results are presented and discussed. Furthermore, in our discussion we use the Kalman filter to filter out estimates of convenience yields and provide some empirical evidence on the Kaldor-Working hypothesis which predicts a negative relationship between convenience yields and levels of inventories.

\footnotetext{
${ }^{9}$ Note also in this context that the contracts which have the smallest standard deviations are those expiring just after the harvesting periods and those which are typically open one year forth (which is reflected in the relatively large number of futures contract observations in the different tables for these expiration months). Hence, since these contracts on average tend to have relatively long times to maturity, the small standard deviations for these contracts can in part be explained by the "Samuelson hypothesis."

${ }^{10}$ Since the seasonal component in (2) enters additively in the description of the logarithm to the spot price in $(1)$.
} 


\subsection{Parameter estimates}

The parameter estimates obtained from the state space estimation approach are tabulated in Table 4.

\section{[ INSERT TABLE 4 ABOUT HERE ]}

We will begin by discussing the estimates of the parameters that describe the dynamics of the stationary and non-stationary state-variables and the parameters added in the state space formulation of the model. Subsequently, we focus on the parameters describing the seasonal components in the futures prices.

The parameter $\mu$ describes the expected appreciation rate of the non-stationary statevariable; as formalized in (3). Changes in $x_{t}$ are associated with permanent price changes and looking at the point estimates in Table 4 all estimates of $\mu$ are of the same magnitude (4.16\% for corn to $5.31 \%$ for wheat). However, due to the relatively high standard deviations on the parameter estimates, none are significantly different from zero.

The estimates in Table 4 indicate that the mean-reversion parameter $\kappa$ is positive and, hence, that the state-variable $z_{t}$, with dynamics as described in (4), is indeed stationary for all the involved commodities. The estimates of $\kappa$ are also of the same magnitude and range from 0.7640 for wheat to 1.0366 for soybeans corresponding to half-lives of 0.9073 years and 0.6687 years, respectively. ${ }^{11}$

Likewise, the volatility structures of the three commodity futures contracts are very similar. The volatilities of the non-stationary component, $\sigma_{x}$, vary in the close range from 0.1584 (corn) to 0.1794 (wheat) while the volatilities of the stationary component, $\sigma_{z}$, are consistently estimated higher for the three commodities and range closely from 0.2201 (corn) to 0.2363 (soybean). Moreover, the "instantaneous" correlation coefficient, $\rho$, between the non-stationary state-variable and the stationary state-variable is negative for all the three commodities.

The risk premia inherent in the specific futures prices are reflected in the estimates of $\lambda_{z}$ and $\mu-\alpha\left(=\lambda_{x}\right)$. No clear pattern is obvious in a comparison of the risk premia estimates across the three commodities although the implied estimates of $\lambda_{x}$ are of the same order of size (from 0.0559 for wheat to 0.0802 for corn). On the other hand, the risk premia associated with the stationary components (i.e. $\lambda_{z}$ ) tend to be negative but the risk premium

\footnotetext{
${ }^{11}$ The half-lives express the time it takes before a given shock to the process is expected to have leveled off by half of the shock; the half-live is in the Ornstein-Uhlenbeck case calculated as $(1 / \kappa) \log 2$.
} 
for corn futures is seemingly significantly different from the risk premium associated with the stationary component in wheat futures and no clear pattern is evident in a comparison across commodities.

For the different commodities, the sum of the two risk premia parameters $\lambda_{x}$ and $\lambda_{z}$ describes the "instantaneous" expected excess return on an investment that have the same risk as the spot commodity price (or a long position in a maturing futures contract). Likewise, these two parameters determine whether futures prices display contango or normal backwardation in the sense that futures prices are below or above expected future spot prices, respectively. Futures prices can be determined by the formula in equation (7) while expected future spot prices can be determined by the analog without risk premia. Inserting the obtained point estimates, Figure 4 displays the futures price divided by the expected future spot price for a given futures contract at different time points. Note that since risk premia are constant, the ratio of the futures price to the expected future spot price is a function of the time to maturity only and, hence, the figure also indicates the ratio of the futures price to the expected future spot price for contracts with different times to maturity. As seen from the figure and implied by the estimates, normal backwardation is the situation for soybeans and wheat. For corn the case is mixed: normal backwardation seems to be the case for long contract maturities while contango seems to the case for short contract maturities.

The parameters $x_{1}$ and $\sigma_{\epsilon}$ are added in the state space formulation of the problem, as described in section 2.3. $x_{1}$ is the estimated starting value of the non-stationary state-variable and while this parameter simply indicates the level of the logarithm of the commodity price in the beginning of the estimation period, it is interesting that the standard deviation on the $x_{1}$ estimate for soybean futures is very large. In fact, looking at the correlation matrix of the parameter estimates (not reported here but provided by the GAUSS ${ }^{\mathrm{TM}}$ maximum likelihood procedures used for the estimation), the correlation coefficients between the parameter estimates on $x_{1}$ and $\lambda_{z}$ are numerically very high, especially for soybean futures $(-0.978)$. This is also reflected in the large standard deviation on the $\lambda_{z}$ estimate for soybeans, and it indicates an identification problem related to the specific parameters and the chosen model structure in the case of soybeans. Furthermore, this might in part explain the unclear pattern in the estimates of the risk premia associated with the stationary components, $\lambda_{z}$, across the commodities in Table 4.

The estimates of $\sigma_{\epsilon}$ describe the inferred standard deviations on the "noise terms" that allow for some deviation between theoretical and observed (log-) futures prices in the state 
space formulation of the model. The point estimates are of the same order of magnitude and vary from 1.71 percent for the corn futures prices to 1.87 percent for the soybean futures prices. One important source of observation "noise" in the specific data is that the settlement prices are set by the regulators at CBOT and thus do not necessarily exactly match market prices at which trading did in fact occur. Other related sources of measurement "noise", in this context, include effects due to price limits and handling of bid-ask spreads; errors in the registration of data could be another source of measurement "noise". Whether these sources of measurement "noise" can account for a standard deviation $\sigma_{\epsilon}$ just below 2 percent is questionable, and this indicates the relevance of extending the model to include additional state-variables for example by allowing for stochastic volatility in the seasonality modeling framework. This, however, would also require additional data that could make inference on this kind of extended model possible (such as commodity options). Anyhow, the estimates of $\sigma_{\epsilon}$ are somehow in line with the estimates in Schwartz (1997). Schwartz (1997) keeps the dimension of the measurement equation constant and estimates the standard deviation of the individual "noise terms" separately (i.e. his representation of the covariance matrix of the measurement error, $H_{n}$ in (9), is a diagonal matrix with different parameters in the diagonal). For example, in his two-factor model the estimate on the "noise term" standard deviation for the shortest oil contract is 2.2 percent in his full sample estimation using five oil futures contracts at each observation date; the similar estimates reported for copper and gold are 3.3 percent and 0.3 percent, respectively.

The estimated seasonal components are described by the estimates of $\gamma_{1}, \gamma_{1}^{*}, \gamma_{2}$, and $\gamma_{2}^{*}$. The number of terms in the sum that describes $s(t)$ as in (2) are $K=2$ in the estimates reported in Table 4; the model was also estimated for other values of $K$ and the choice of $K$ $=2$ was based on the Akaike Information Criterion (AIC); see e.g. Harvey (1981), p. 176.

The forms of the estimated seasonal components are displayed in Figure 5.

\section{[ INSERT FIGURE 5 ABOUT HERE ]}

For corn and soybean the deterministic seasonal price components peak in June and July about two to three months prior to the beginning of the harvest of those commodities, which occur from mid to late September and through October. The harvesting season for wheat is earlier due to the winter wheat which is usually harvested in late spring and early summer and accounts for more than 70 percent of the US wheat production; spring wheat is harvested from September through October. The estimation results suggest that the seasonal component in 
wheat prices peaks in March-April which is about two months prior to the winter wheat harvest. $^{12}$

In general, the deterministic seasonal components for the three commodities, as displayed in Figure 5, peak about two to three months before the beginning of the harvest. In the period until the end of the harvest the seasonal price component decreases and, hence, ceteris paribus the convenience yield on the commodity must be high if the marginal investors carrying inventory positions have to break even in this period. In the period before the harvest inventories are usually scarce and this is a period where an owner of inventories may gain from temporary unexpected high demands for the specific commodity or adverse weather conditions which will reduce the size of the crop and the supply of next year. These observations are consistent with the Kaldor-Working hypothesis that predicts a negative relationship between the convenience yield and the stock of inventory of a given commodity.

\subsection{Empirical evidence on the Kaldor-Working hypothesis}

In this section we will provide a more extensive empirical analysis of the Kaldor-Working hypothesis by regressing estimated (net) convenience yields on stocks of inventory for corn, soybean, and wheat. We will start by describing how the (net) convenience yields for the regression analysis are constructed using our modeling framework from section 2.

As noted earlier, the convenience yield of a commodity may be defined as the value of the services which accrues to the owner of physical inventory but not to the owner of a contract for future delivery; hence, the convenience yield will be reflected in the spread between the spot commodity price (or a very short maturity futures price) and the longer maturity futures prices. Moreover, the owner of physical inventory can alternatively earn interest on the capital invested in the physical inventory. The net convenience yield is defined as the convenience yield plus the interest forgone by having capital invested in physical inventory. Formally, as a definition of the net convenience yield at time $t$ and over the next period of length $\Delta$, we will use

$$
\delta_{t}(\Delta)=r_{t}(\Delta)-\frac{\log F_{t}(t+\Delta)-\log F_{t}(t)}{\Delta}
$$

where $r_{t}(\Delta)$ is the appropriate interest rate (i.e. zero-coupon yield) between $t$ and $t+\Delta$ and $F_{t}(t)$ must equal the spot commodity price. This definition is equivalent to the usual textbook

\footnotetext{
${ }^{12}$ This and additional information on growth cycles and critical periods of weather influence on crop sizes of corn, soybeans, and wheat can be found in the CBOT General Information Series, No. 6-8.
} 
definition (see e.g. Hull (2000), pp. 72-73) where the convenience yield is defined implicitly by the cost of carry relation: $F_{t}(t+\Delta)=F_{t}(t) e^{\left(r_{t}(\Delta)-\delta_{t}(\Delta)\right) \Delta}$. In the above definition of convenience yields we have ignored storage costs and, consequently, the net convenience yields estimated subsequently are downward biased; implications of this for the interpretation of results in the empirical analysis of the Kaldor-Working hypothesis are discussed later.

Inserting the expression for futures prices in (7) into the definition (11), we obtain the following description of the convenience yield over the next period $\Delta$ :

$$
\delta_{t}(\Delta)=r_{t}(\Delta)-\frac{s(t+\Delta)-s(t)}{\Delta}-\frac{A(\Delta)}{\Delta}+\frac{1}{\Delta}\left(1-e^{-\kappa \Delta}\right) z_{t}
$$

Besides the seasonal component, the convenience yield depends on a deterministic risk component and the current position of the stationary state-variable $z_{t}$. The convenience yield is negatively related to the slope of the seasonal component since owners of inventory positions, ceteris paribus, must experience a high (low) convenience yield to compensate for an expected commodity spot price depreciation (appreciation). The deterministic risk component, $A(\Delta) / \Delta$, depends on risk premia as well as volatilities through the effects of Jensen's inequality. Anyhow, for a fixed $\Delta$ (as in the regressions below) this enters as a constant term in the cross-section of convenience yields for a given commodity and, hence, should not matter for inference about the validity of a negative relationship between convenience yields and stocks of inventory, as predicted by the Kaldor-Working hypothesis. Finally, the convenience yield is positively related to the stationary state-variable $z_{t}$. If $z_{t}$ is positive, the expected rate of change in $z_{t}$ is negative (due to mean-reversion of the Ornstein-Uhlenbeck process), and once again the intuition is that owners of inventory positions, ceteris paribus, must experience a high convenience yield to compensate for the expected commodity spot price depreciation; and vice versa for negative values of $z_{t}$.

The following empirical analysis of the Kaldor-Working hypothesis is based on threemonths $(\Delta=0.25)$ net convenience yields. Since the convenience yield is an affine function of the state-variables we have used the state space formulation and the Kalman filter to estimate the three-month convenience yields at the relevant dates. As described in for example Harvey (1989), the Kalman filter in this case provides the conditional expectations of the state-variables recursively given all information available at the given points in time. The interest rates used in constructing net convenience yields are based on three-month Treasury bill rates obtained from the Federal Reserve Bank of Chicago. 
Formally, we ran the following non-linear regression: ${ }^{13}$

$$
\delta_{t}(0.25)=a+b\left(I_{t} / Q_{t}\right)^{c}+u_{t}
$$

where $a, b$, and $c$ (as well as the standard deviation $\sigma_{u}$ of the "white noise" term $u_{t}$ ) are constant parameters to be estimated. The independent variable $I_{t} / Q_{t}$ in (13) is inventories at date $t, I_{t}$, normalized by total US production $Q_{t}$. The data on stocks of inventory is taken from various issues of the USDA Statistical Bulletin. The data on stocks of inventory are available on a quarterly basis from 1972 until 1997 but the precise months for which the inventories are recorded and announced have changed over the period. Hence, for soybeans we have stocks of inventory recorded for the following months: January, March, April, June, July, September, and December. For corn and wheat there are additionally observations recorded for October in some of the years. $Q_{t}$ is constructed as a three-year average of the officially announced US production in the three years prior to time $t$. The dependent variable is the filtered three-month net convenience yield; specifically, this variable is constructed as the average of the filtered net convenience yields, using (12), for the second and third Wednesday for the particular months for which the stocks of inventory $I_{t}$ have been recorded.

Regression results obtained by the method of non-linear least squares are tabulated in Tables 5 and the data and "fitted" relationships between filtered convenience yields and stocks of inventory are displayed in Figure 6 , Figure 7, and Figure 8.

\section{[ INSERT TABLE 5, FIGURE 6, FIGURE 7, AND FIGURE 8 ABOUT HERE ]}

The estimation results tabulated in Table 5 include both results from the regression equation (13) as well as a seasonal adjusted version which include dummy variables indicating the observation months. The most interesting parameter, in our context and in the context of the Kaldor-Working hypothesis, is $b$ which is predicted to be negative (whenever $c>0$ ). For all commodities in the unadjusted regressions the parameter $b$ is, in fact, negative and significantly different from zero. In the seasonally adjusted regressions $b$ is negative, but not significant in the case of wheat due to multicollinearity in this particular regression.

The explanatory power of the non-linear regression model in (13) is reflected in the coefficients of multiple correlation, $R^{2}$, as reported in Table 5. The coefficients of multiple

\footnotetext{
${ }^{13}$ The specific form of the regression used to examine the validity of the Kaldor-Working hypothesis is similar to the form used by Brennan (1991) in the case of three precious metals and the commercial commodities: copper, heating oil, lumber, and plywood.
} 
correlation are of the same magnitude as for the commercial commodities in the framework of Brennan (1991), but higher than for the case of heating oil $\left(R^{2}=0.17\right)$ which is reported to display a clear seasonal pattern that is not taken care of the way he estimates the convenience yield. ${ }^{14}$ The higher explanatory power compared to the case of heating oil in Brennan (1991) can thus be explained by the fact that in the present framework the seasonal feature of convenience yields are explicitly modeled and in principle taken care of when using (12) to filter out the relevant convenience yields.

The relationships between convenience yields and inventories are suggested negative by the regression results in Table 5. However, following the reasoning behind the Kaldor-Working hypothesis, one would conjecture that convenience yields are especially high for very low levels of stocks of inventory while leveling of at zero for very high levels of stocks of inventory. This suggest that the estimated functional forms should turn out to be convex, as is only the case for soybeans in Figure 7. In the estimation of net convenience yields we have ignored storage costs and, as a consequence, the filtered net convenience yields are downward biased by the storage costs. Furthermore, if there are sufficiently increasing marginal costs of storage this could explain the functional forms estimated for corn and wheat, as displayed in Figure 6 and Figure 8. Fama and French (Table 2, p. 59, 1987) report storage costs and costs of loading and unloading various commodities at warehouses for June 1984 (which is about in the middle of our sample period). The monthly storage costs per dollar of the June 1984 spot price are reported to be: $1.41 \%$ for corn, $0.64 \%$ for soybeans, and $1.39 \%$ for wheat. Or, on an annualized basis: $18.30 \%$ for corn, $7.96 \%$ for soybeans, and $18.02 \%$ for wheat. Storage costs are variable over time and depend on the aggregate quanta that need to be stored but these annualized storage costs indicate the order of magnitude that should be added to the filtered convenience yields in order to reflect the total costs of carry. This explains, we believe, why some of the filtered convenience yields, as displayed in Figure 6, Figure 7, and Figure 8, are substantially negative. Moreover, the figures are consistent with higher storage costs on corn and wheat than soybeans since the lower bound on convenience yields is less negative in the case of soybeans.

What can be inferred from the seasonal adjusted regressions? The Kaldor-Working hypothesis only relates convenience yields to stocks of inventory, not to the season. However,

\footnotetext{
${ }^{14}$ This is pointed out by Brennan (1991, p. 66, line 1-2 and footnote 23). However, note also that the exact construction of the independent variable in Brennan (1991) is different from the construction in our analysis. In particular, he uses sales instead of production when normalizing inventories.
} 
the outlook for opportunities to profit from temporary shortages of a commodity, seen from the viewpoint of an owner of a given inventory position, might well depend on whether the harvesting period is coming up or not. The seasonal adjusted regressions contain twenty additional dummy variables and only one parameter is significantly different from zero at a five percent significance level (the July dummy variable for corn). However, $F$-test probabilities under the null hypothesis that the dummy variable parameters are all zero are $0.7 \%$ for corn, $3.4 \%$ for soybean, and less than $0.1 \%$ for wheat; hence, the null hypothesis is rejected on a five percent significance level for all the involved commodities. This indicates at least some relevance of an interaction effect between convenience yields, stocks of inventory, and the season; this is also indicated by the higher corrected $R^{2} \mathrm{~s}$ which make some allowance for the extra explanatory dummy variables included in the seasonally adjusted regressions. Furthermore, the point estimates of the dummy parameters indicate that for a given level of stocks of inventory, the convenience yields are higher just prior to the harvesting periods; this is suggested by the relatively high point estimates on the July dummy for corn, the July dummy for soybean, and the April dummy for wheat. An interpretation and perspective on this observation is that this is a period where adverse weather conditions are able to severely reduce crop sizes and make abrupt changes in the anticipated supply for the following year, which will make a given inventory position particularly convenient and appreciated for example in order to keep a production process running.

\section{$5 \quad$ Summary and conclusions}

We have provided a framework for estimating model parameters, and especially seasonal parameters, using both the time-series characteristics and cross-sectional characteristics of agricultural commodity futures prices. Estimation results were provided in the case of corn, soybeans, and wheat using weekly panel-data observations of futures prices from CBOT for the period 1972 to 1997 . Besides the estimated seasonal features the estimation results suggested that normal backwardation is the situation for soybeans and wheat while the situation for corn is mixed: normal backwardation seems to the case for long contract maturities while contango seems to be the case for short contract maturities.

Using the basic modeling framework allowed us to estimate implied net convenience yields using the Kalman filter and this was applied in an empirical investigation of the theory of storage and, in particular, the Kaldor-Working hypothesis that convenience yields and levels 
of inventories are negatively related. The empirical analysis verified a significant negative relationship

Future research could extend the basic continuous-time no-arbitrage model in various ways by introducing for example stochastic volatility or discontinuities (jumps) in the commodity price process as well as a seasonality feature in the volatilities. In this case, it seems that estimation of the model could benefit from including additional data such as prices on commodity options. While a state space formulation of the model could in this case still be possible and relevant for estimation, the standard Kalman filter maximum likelihood methodology would have to be modified in order to account for the non-linearities introduced by e.g. including option prices.

Finally, the empirical analysis of the theory of storage and the Kaldor-Working hypothesis indicates interesting basic issues that may benefit and be better understood by analysis in a formal equilibrium framework. These issues include the interactions of convenience yields, stocks of inventory, the production cycle, and season. 


\section{References}

Bessembinder, H.; J. F. Coughenour; P. J. Seguin; and M. M. Smoller (1995). "Mean Reversion in Equilibrium Asset Prices: Evidence from the Futures Term Structure". Journal of Finance, 50(1), 361-375.

Bessembinder, H.; J. F. Coughenour; P. J. Seguin; and M. M. Smoller (1996). "Is There a Term Structure of Futures Volatilities? Reevaluating the Samuelson Hypothesis". Journal of Derivatives, 4, 45-58.

Bjerksund, P. (1991). "Contingent Claims Evaluation when the Convenience Yield is Stochastic: Analytical Results". Working paper, Norwegian School of Economics and Business Administration.

Brennan, M. J. (1958). "The Supply of Storage". American Economic Review, 48, 50-72.

Brennan, M. J. (1991). "The Price of Convenience and the Valuation of Commodity Contingent Claims". In D. Lund \& B. Øksendal (eds.), Stochastic Models and Option Values, pp. 33-71. Elsevier Science Publishers B.V. (North-Holland).

Brennan, M. J. and E. S. Schwartz (1985). "Evaluating Natural Resource Investments". Journal of Business, 58, 133-155.

Chambers, M. and R. Bailey (1996). "A Theory of Commodity Price Fluctuations". Journal of Political Economy, 104, 924-957.

Chicago Board of Trade (1997). Weather and the Corn Market. (Chicago Board of Trade, General Information Series 6).

Chicago Board of Trade (1997). Weather and the Soybean Market. (Chicago Board of Trade, General Information Series 7).

Chicago Board of Trade (1997). Weather and the Wheat Market. (Chicago Board of Trade, General Information Series 8).

Cortazar, G. and E. S. Schwartz (1994). "The Evaluation of Commodity Contingent Claims". Journal of Derivatives, 1, 27-39.

Cox, J. C.; J. E. Ingersoll, Jr.; and S. A. Ross (1981). "The Relation between Forward Prices and Futures Prices". Journal of Financial Economics, 9(4), 321-346. 
Cox, J. C.; J. E. Ingersoll, Jr.; and S. A. Ross (1985). "A Theory of the Term Structure of Interest Rates". Econometrica, 53(2), 385-407.

Deaton, A. and G. Laroque (1992). "On the Behavior of Commodity Prices". Review of Economic Studies, 59, 1-23.

Deaton, A. and G. Laroque (1996). "Competitive Storage and Commodity Price Dynamics". Journal of Political Economy, 104, 896-923.

Dixit, A. K. and R. S. Pindyck (1994). Investment under Uncertainty. Princeton University Press, Princeton, New Jersey.

Duffie, J. D. (1996). Dynamic Asset Pricing Theory. Princeton University Press, Princeton, New Jersey, Second Edition.

Fama, E. F. and K. R. French (1987). "Commodity Futures Prices: Some Evidence on Forecast Power, Premiums, and the Theory of Storage". Journal of Business, 60(1), $55-73$.

Gibson, R. and E. S. Schwartz (1990). "Stochastic Convenience Yield and the Pricing of Oil Contingent Claims". Journal of Finance, 45, 959-976.

Gibson, R. and E. S. Schwartz (1991). "Valuation of Long Term Oil-Linked Assets". In D. Lund \& B. Øksendal (eds.), Stochastic Models and Option Values, pp. 73-101. Elsevier Science Publishers B.V. (North-Holland).

Harvey, A. C. (1981). The Econometric Analysis of Time Series. Philip Alan Publishers Limited.

Harvey, A. C. (1989). Forecasting, structural time series models and the Kalman filter. Cambridge University Press.

Hilliard, J. E. and J. Reis (1998). "Valuation of Commodity Futures and Options under Stochastic Convenience Yields, Interest Rates, and Jump Diffusions in the Spot". Journal of Financial and Quantitative Analysis, 33, 61-86.

Hull, J. C. (2000). Options, Futures, \& Other Derivatives. Prentice-Hall, Upper Saddle River, New Jersey, Fourth International Edition. 
Jamshidian, F. and M. Fein (1990). "Closed-Form Solutions for Oil Futures and European Options in the Gibson-Schwartz Model: A Note". Working paper, Merrill Lynch Capital Markets.

Kaldor, N. (1939). "Speculation and Economic Stability". Review of Economic Studies, 7, 1-27.

Miltersen, K. R. and E. S. Schwartz (1998). "Pricing of Options on Commodity Futures with Stochastic Term Structures of Convenience Yields and Interest Rates". Journal of Financial and Quantitative Analysis, 33, 33-59.

Routledge, B. R.; D. J. Seppi; and C. S. Spatt (1998). "The Spark Spread: An Equilibrium Model of Cross-Commodity Price Relationship in Electricity". Working paper, Graduate School of Industrial Administration, Carnegie Mellon University.

Routledge, B. R.; D. J. Seppi; and C. S. Spatt (1999). "Equilibrium Forward Curves for Commodities". Working paper, Graduate School of Industrial Administration, Carnegie Mellon University.

Samuelson, P. (1965). "Proof that Properly Anticipated Prices Fluctuate Randomly". Industrial Management Review, 6, 41-49.

Schwartz, E. S. (1997). "The Stochastic Behvior of Commodity Prices: Implications for Valuation and Hedging". Journal of Finance, 52(3), 923-973.

Schwartz, E. S. and J. E. Smith (1997). "Short-Term Variation and Long-Term Dynamics in Commodity Prices". Finance Working Paper \#14-97, The John E. Anderson Graduate School of Management, University of California, Los Angeles.

Sørensen, C. (1997). "An Equilibrium Approach to Pricing Foreign Currency Options". European Financial Management, 3(1), 63-84.

Telser, L. G. (1958). "Futures Trading and the Storage of Cotton and Wheat". Journal of Political Economy, 66, 233-255.

United States Department of Agriculture. Stocks of Grains, Oilseed, and Hay - Final Estimates by States. Statistical Bulletin (various years and issues), USDA Economics and Statistics Service Crop Report Board. 
Williams, J. and B. Wright (1991). Storage and Commodity Markets. Cambridge University Press, Cambridge, England.

Working, H. (1948). "Theory of the Inverse Carrying Charge in Futures Markets". Journal of Farm Economics, 30, 1-28.

Working, H. (1949). "The Theory of the Price of Storage". American Economic Review, 39, $1254-1262$.

Wright, B. and J. Williams (1989). "A Theory of Negative Prices for Storage". Journal of Futures Markets, 9, 1-13. 
Table 1: Summary statistics for corn futures

\begin{tabular}{|cccc|}
\hline Futures contracts & Number of observations & Average price & Standard deviation \\
ALL & 9124 & 264.17 & 52.20 \\
\hline & Grouped into expiration months & \\
\hline Futures contracts & Number of observations & Average price & Standard deviation \\
May & 1870 & 263.18 & 52.14 \\
Jul & 1730 & 267.78 & 54.47 \\
Sep & 1798 & 271.42 & 54.76 \\
Dec & 1640 & 262.05 & 51.88 \\
& 2086 & 257.49 & 47.05 \\
\hline Futures contracts & Number of observations & Average price & Standard deviation \\
1. closest & 1335 & 260.59 & 60.31 \\
2. closest & 1335 & 262.74 & 57.45 \\
3. closest & 1335 & 264.57 & 55.41 \\
4. closest & 1335 & 265.27 & 53.52 \\
5. closest & 1332 & 265.19 & 52.23 \\
6. closest & 1231 & 267.79 & 48.57 \\
7. closest & 787 & 262.33 & 34.98 \\
8. closest & 261 & 268.29 & 19.56 \\
9. closest & 143 & 261.26 & 12.12 \\
10. closest & 30 & & 6.64 \\
\hline
\end{tabular}

Notes: Futures prices are in cents per bushel. The dataset consists of 1335 weekly observations from $1 / 2 / 72$ to $7 / 30 / 97$. 
Table 2: Summary statistics for soybean futures

\begin{tabular}{|c|c|c|c|}
\hline Futures contracts & Number of observations & Average price & Standard deviation \\
\hline ALL & 11821 & 640.42 & 111.28 \\
\hline \multicolumn{4}{|c|}{ Grouped into expiration months } \\
\hline Futures contracts & Number of observations & Average price & Standard deviation \\
\hline Jan & 1688 & 632.09 & 109.89 \\
\hline Mar & 1650 & 640.51 & 110.43 \\
\hline May & 1650 & 648.89 & 113.67 \\
\hline Jul & 1856 & 655.76 & 112.25 \\
\hline Aug & 1503 & 649.04 & 119.53 \\
\hline Sep & 1495 & 633.55 & 110.71 \\
\hline Nov & 1979 & 624.65 & 100.61 \\
\hline \multicolumn{4}{|c|}{ Grouped into time to maturity } \\
\hline Futures contracts & Number of observations & Average price & Standard deviation \\
\hline 1. closest & 1335 & 635.94 & 123.95 \\
\hline 2. closest & 1335 & 639.70 & 123.07 \\
\hline 3. closest & 1335 & 641.11 & 119.70 \\
\hline 4. closest & 1335 & 639.76 & 116.48 \\
\hline 5. closest & 1335 & 638.95 & 115.66 \\
\hline 6. closest & 1334 & 638.33 & 114.25 \\
\hline 7. closest & 1315 & 638.72 & 110.53 \\
\hline 8. closest & 1205 & 650.86 & 96.72 \\
\hline 9. closest & 823 & 645.73 & 75.38 \\
\hline 10. closest & 288 & 640.53 & 49.48 \\
\hline 11. closest & 146 & 627.01 & 33.25 \\
\hline 12. closest & 28 & 608.64 & 14.12 \\
\hline 13. closest & 7 & 604.64 & 5.16 \\
\hline
\end{tabular}

Notes: Futures prices are in cents per bushel. The dataset consists of 1335 weekly observations from $1 / 2 / 72$ to $7 / 30 / 97$. 
Table 3: Summary statistics for wheat futures

\begin{tabular}{|cccc|}
\hline Futures contracts & Number of observations & Average price & Standard deviation \\
ALL & 8028 & 357.26 & 75.26 \\
\hline \multicolumn{4}{c}{ Grouped into expiration months } \\
\hline Futures contracts & Number of observations & Average price & Standard deviation \\
May & 1571 & 366.92 & 78.17 \\
Jul & 1479 & 360.13 & 77.71 \\
Sep & 1785 & 347.57 & 67.86 \\
Dec & 1503 & 349.68 & 75.20 \\
\hline Futures contracts & Number of observations & Average price & Standard deviation \\
1. closest & 1690 & 362.74 & 75.98 \\
2. closest & 1335 & 355.29 & 79.46 \\
3. closest & 1335 & 355.44 & 79.00 \\
4. closest & 1335 & 354.63 & 77.90 \\
5. closest & 1335 & 357.34 & 77.07 \\
6. closest & 1294 & 364.91 & 75.69 \\
7. closest & 1043 & 357.05 & 66.98 \\
8. closest & 242 & 369.34 & 38.71 \\
9. closest & 92 & 390.65 & 33.98 \\
\hline
\end{tabular}

Notes: Futures prices are in cents per bushel. The dataset consists of 1335 weekly observations from $1 / 2 / 72$ to $7 / 30 / 97$. 
Table 4: Parameter estimates

\begin{tabular}{|c|c|c|c|}
\hline & Corn futures & Soybean futures & Wheat futures \\
\hline$\mu$ & $\begin{array}{c}0.0416 \\
(0.0206)\end{array}$ & $\begin{array}{c}0.0433 \\
(0.0267)\end{array}$ & $\begin{array}{c}0.0531 \\
(0.0336)\end{array}$ \\
\hline$\kappa$ & $\begin{array}{c}0.7744 \\
(0.0239)\end{array}$ & $\begin{array}{c}1.0366 \\
(0.0299)\end{array}$ & $\begin{array}{c}0.7640 \\
(0.0333)\end{array}$ \\
\hline$\sigma$ & $\begin{array}{c}0.1585 \\
(0.0052)\end{array}$ & $\begin{array}{c}0.1785 \\
(0.0050)\end{array}$ & $\begin{array}{c}0.1794 \\
(0.0063)\end{array}$ \\
\hline$v$ & $\begin{array}{c}0.2201 \\
(0.0077)\end{array}$ & $\begin{array}{c}0.2363 \\
(0.0072)\end{array}$ & $\begin{array}{c}0.2253 \\
(0.0099)\end{array}$ \\
\hline$\rho$ & $\begin{array}{l}-0.3116 \\
(0.0427)\end{array}$ & $\begin{array}{l}-0.1344 \\
(0.0379)\end{array}$ & $\begin{array}{l}-0.2590 \\
(0.0523)\end{array}$ \\
\hline$\alpha$ & $\begin{array}{l}-0.0386 \\
(0.0025)\end{array}$ & $\begin{array}{l}-0.0204 \\
(0.0027)\end{array}$ & $\begin{array}{l}-0.0028 \\
(0.0036)\end{array}$ \\
\hline$\lambda_{z}$ & $\begin{array}{l}-0.1011 \\
(0.0376)\end{array}$ & $\begin{array}{l}-0.0292 \\
(0.1472)\end{array}$ & $\begin{array}{c}0.0002 \\
(0.0131)\end{array}$ \\
\hline$x_{1}$ & $\begin{array}{c}4.8738 \\
(0.0558)\end{array}$ & $\begin{array}{c}5.7225 \\
(0.1403)\end{array}$ & $\begin{array}{c}4.9257 \\
(0.0399)\end{array}$ \\
\hline$\sigma_{\epsilon}$ & $\begin{array}{c}0.0171 \\
(0.0001)\end{array}$ & $\begin{array}{c}0.0187 \\
(0.0001)\end{array}$ & $\begin{array}{c}0.0178 \\
(0.0002)\end{array}$ \\
\hline$\gamma_{1}$ & $\begin{array}{l}-0.0228 \\
(0.0003)\end{array}$ & $\begin{array}{l}-0.0182 \\
(0.0003)\end{array}$ & $\begin{array}{c}0.0162 \\
(0.0003)\end{array}$ \\
\hline$\gamma_{1}^{*}$ & $\begin{array}{c}0.0081 \\
(0.0003)\end{array}$ & $\begin{array}{c}0.0085 \\
(0.0003)\end{array}$ & $\begin{array}{c}0.0202 \\
(0.0003)\end{array}$ \\
\hline$\gamma_{2}$ & $\begin{array}{c}0.0029 \\
(0.0002)\end{array}$ & $\begin{array}{c}0.0031 \\
(0.0003)\end{array}$ & $\begin{array}{l}-0.0057 \\
(0.0003)\end{array}$ \\
\hline$\gamma_{2}^{*}$ & $\begin{array}{c}0.0054 \\
(0.0004)\end{array}$ & $\begin{array}{c}0.0058 \\
(0.0002)\end{array}$ & $\begin{array}{l}-0.0081 \\
(0.0004)\end{array}$ \\
\hline $\begin{array}{l}\text { log-likelihood } \\
\text { function }\end{array}$ & 21856 & 27591 & 18654 \\
\hline
\end{tabular}

Notes: Standard errors in parentheses. 
Table 5: Convenience yields regressed on stocks of inventory

\begin{tabular}{|c|c|c|c|c|c|c|}
\hline \multirow[b]{2}{*}{$a$} & \multicolumn{2}{|c|}{ Corn } & \multicolumn{2}{|c|}{ Soybean } & \multicolumn{2}{|c|}{ Wheat } \\
\hline & $\begin{array}{c}0.1427 \\
(0.0432)\end{array}$ & $\begin{array}{l}-0.0354 \\
(0.1205)\end{array}$ & $\begin{array}{c}0.2676 \\
(0.0835)\end{array}$ & $\begin{array}{c}0.2017 \\
(0.1632)\end{array}$ & $\begin{array}{c}0.1930 \\
(0.0446)\end{array}$ & $\begin{array}{c}0.8212 \\
(7.8039)\end{array}$ \\
\hline$b$ & $\begin{array}{l}-0.2973 \\
(0.0482)\end{array}$ & $\begin{array}{l}-0.2120 \\
(0.0477)\end{array}$ & $\begin{array}{l}-0.4432 \\
(0.0758)\end{array}$ & $\begin{array}{l}-0.4140 \\
(0.0719)\end{array}$ & $\begin{array}{l}-0.2008 \\
(0.0531)\end{array}$ & $\begin{array}{l}-0.7457 \\
(7.8120)\end{array}$ \\
\hline$c$ & $\begin{array}{c}1.3157 \\
(0.4308)\end{array}$ & $\begin{array}{c}1.6847 \\
(0.7618)\end{array}$ & $\begin{array}{c}0.8653 \\
(0.3771)\end{array}$ & $\begin{array}{c}1.4576 \\
(0.8368)\end{array}$ & $\begin{array}{c}1.8054 \\
(0.6967)\end{array}$ & $\begin{array}{c}0.1032 \\
(1.1663)\end{array}$ \\
\hline$\sigma_{u}$ & $\begin{array}{c}0.1290 \\
(0.0090)\end{array}$ & $\begin{array}{c}0.1146 \\
(0.0080)\end{array}$ & $\begin{array}{c}0.1527 \\
(0.0107)\end{array}$ & $\begin{array}{c}0.1398 \\
(0.0098)\end{array}$ & $\begin{array}{c}0.1401 \\
(0.0098)\end{array}$ & $\begin{array}{c}0.1165 \\
(0.0081)\end{array}$ \\
\hline Jan & - & - & - & - & - & - \\
\hline Mar & - & $\begin{array}{c}0.0418 \\
(0.1163)\end{array}$ & - & $\begin{array}{l}-0.0932 \\
(0.1526)\end{array}$ & - & $\begin{array}{c}0.0379 \\
(0.1252)\end{array}$ \\
\hline Apr & - & $\begin{array}{c}0.0635 \\
(0.1157)\end{array}$ & - & $\begin{array}{l}-0.0222 \\
(0.1525)\end{array}$ & - & $\begin{array}{c}0.1296 \\
(0.1232)\end{array}$ \\
\hline Jun & - & $\begin{array}{c}0.1727 \\
(0.1152)\end{array}$ & - & $\begin{array}{l}-0.0294 \\
(0.1517)\end{array}$ & - & $\begin{array}{l}-0.0058 \\
(0.1241)\end{array}$ \\
\hline Jul & - & $\begin{array}{c}0.3366 \\
(0.1275)\end{array}$ & - & $\begin{array}{c}0.2622 \\
(0.1654)\end{array}$ & - & $\begin{array}{l}-0.1306 \\
(0.1378)\end{array}$ \\
\hline Sep & - & $\begin{array}{c}0.1844 \\
(0.1201)\end{array}$ & - & $\begin{array}{l}-0.0088 \\
(0.1507)\end{array}$ & - & $\begin{array}{l}-0.1319 \\
(0.1204)\end{array}$ \\
\hline Oct & - & $\begin{array}{c}0.1084 \\
(0.1143)\end{array}$ & - & - & - & $\begin{array}{l}-0.1373 \\
(0.1175)\end{array}$ \\
\hline Dec & - & $\begin{array}{c}0.1147 \\
(0.1176)\end{array}$ & - & $\begin{array}{c}0.0546 \\
(0.1572)\end{array}$ & - & $\begin{array}{l}-0.0308 \\
(0.1224)\end{array}$ \\
\hline$R^{2}$ & 0.3605 & 0.4959 & 0.3589 & 0.4629 & 0.2603 & 0.4884 \\
\hline $\bar{R}^{2}$ & 0.3476 & 0.4466 & 0.3458 & 0.4098 & 0.2455 & 0.4328 \\
\hline $\begin{array}{l}\text { Number of } \\
\text { observations }\end{array}$ & 102 & 102 & 101 & 101 & 103 & 103 \\
\hline
\end{tabular}

Notes: Standard errors in parentheses. January is the base case month in the seasonally adjusted regressions. $R^{2}$ is the coefficient of multiple correlation while $\bar{R}^{2}$ is the corrected $R^{2}$. 


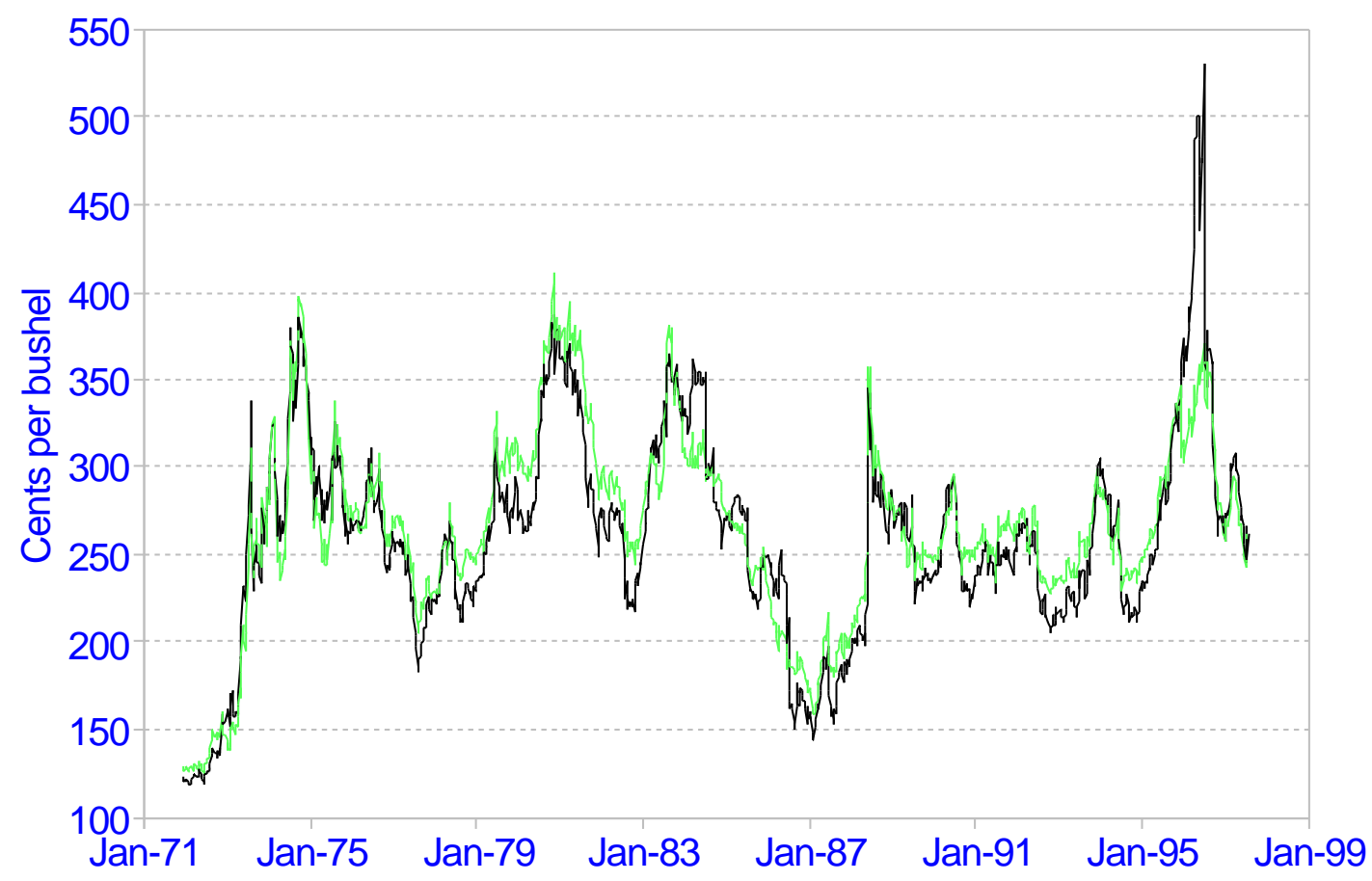

Figure 1: Time series of corn futures prices. The figure displays the futures prices on the contracts with the shortest time to maturity and the fourth shortest time to maturity over the full sample period. 


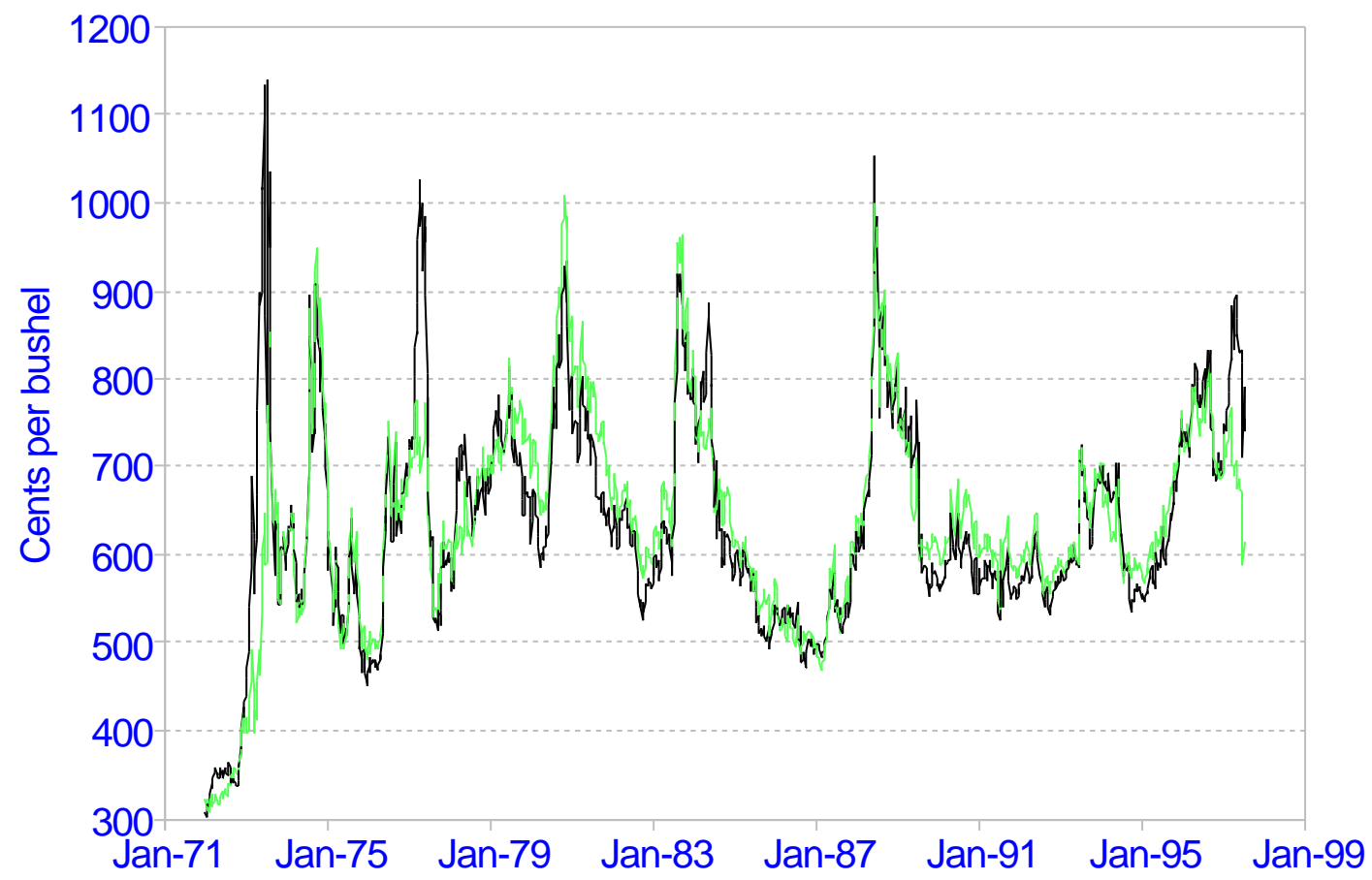

Figure 2: Time series of soybean futures prices. The figure displays the futures prices on the contracts with the shortest time to maturity and the fifth shortest time to maturity over the full sample period. 


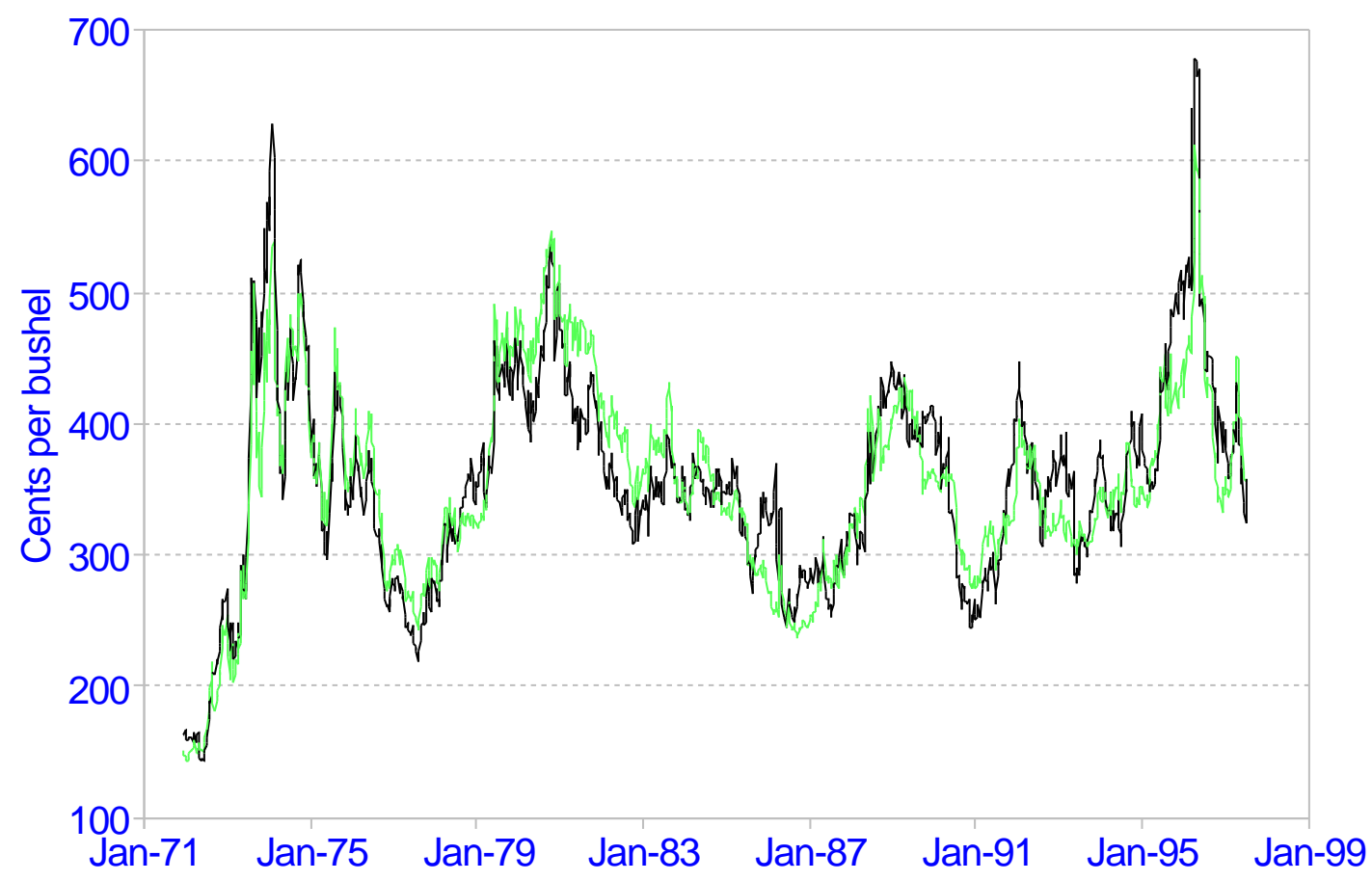

\section{1. closest maturity - 4. closest maturity}

Figure 3: Time series of wheat futures prices. The figure displays the futures prices on the contracts with the shortest time to maturity and the fourth shortest time to maturity over the full sample period. 


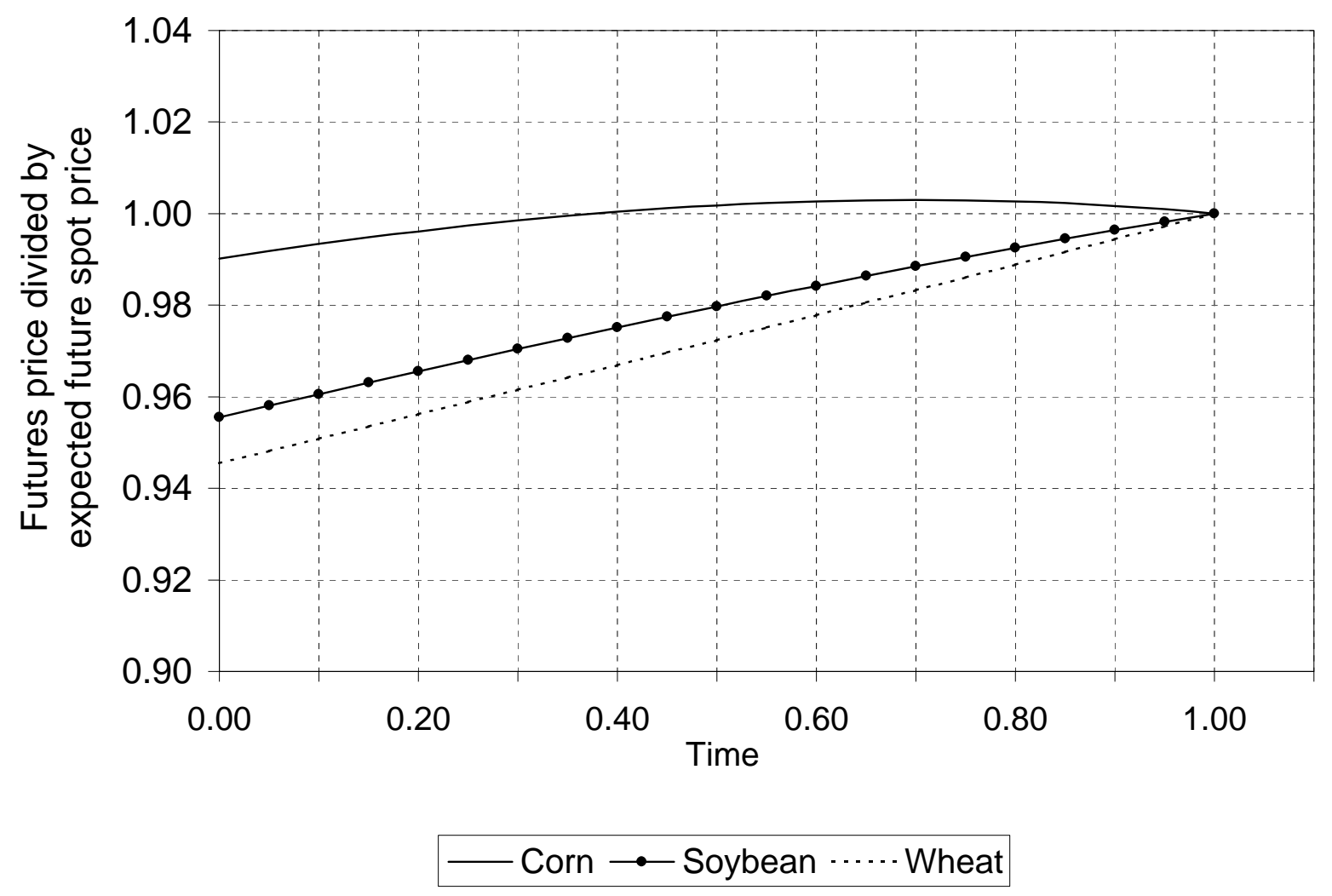

Figure 4: Futures prices divided by expected future spot prices for corn, soybean, and wheat. The figure displays the ratio of the futures price to the expected future spot price as implied by the modeling in section 2 and the estimates in Table 4 . The contracts expire at time $\tau=1$ and the figure displays whether the basis is positive or negative (i.e. futures price divided by expected spot price is above one or below one) at different time points prior to maturity. The futures prices are obtained from the formula in (7) while the expected future spot prices are obtained from the analog without risk premia; $F_{t}(\tau) / \mathrm{E}_{\mathrm{t}}\left[P_{\tau}\right]$ $=e^{-\lambda_{x}(\tau-t)-\left(\lambda_{z} / \kappa\right)\left(1-e^{-\kappa(\tau-t)}\right)}$. 


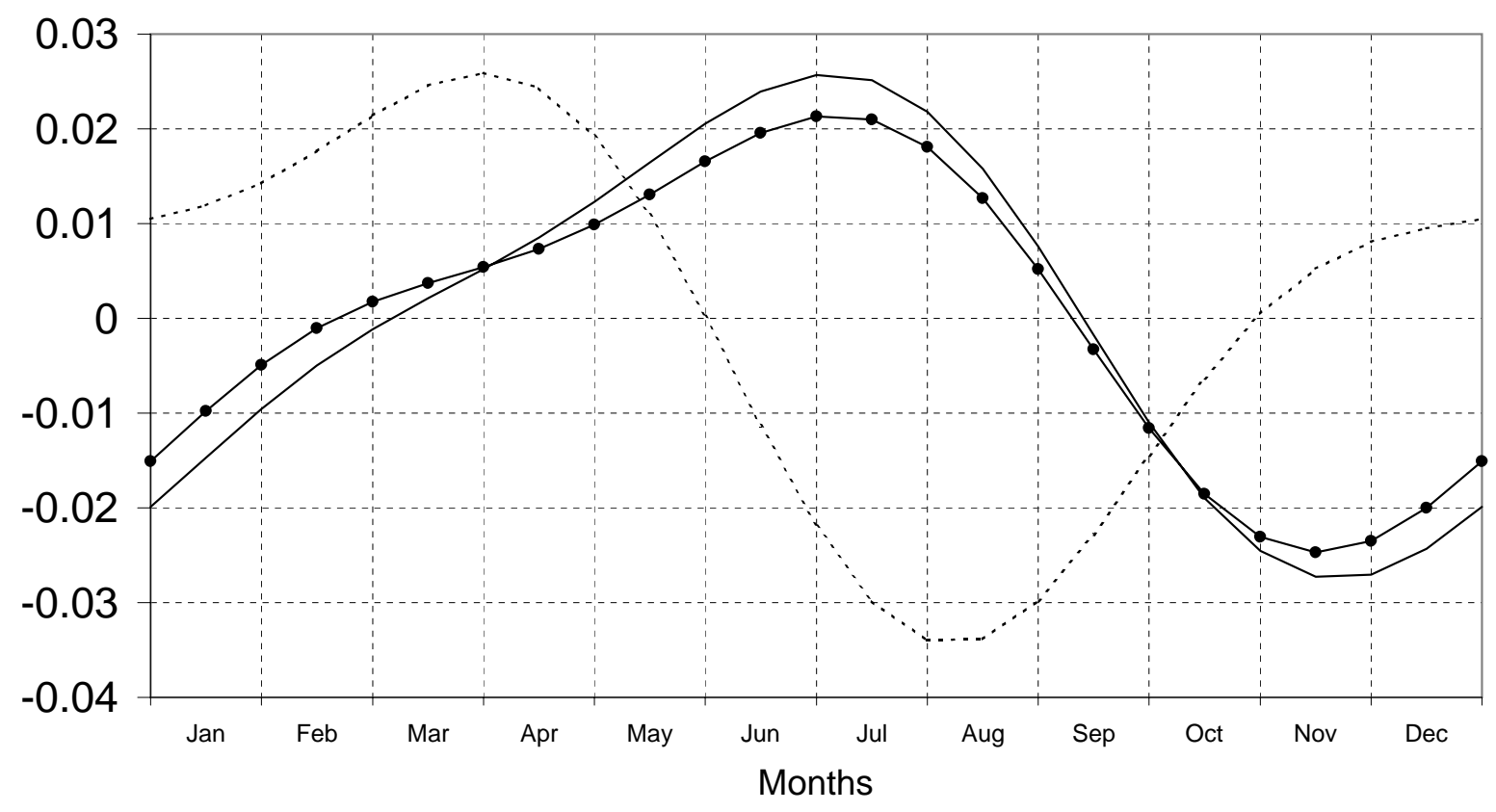

— Corn $\rightarrow$ Soybean $\cdots \cdot$...Wheat

Figure 5: Estimated seasonal patterns for corn, soybean, and wheat. The figure is obtained by substituting the parameter estimates in Table 4 into the function $s(t)$, as defined in $(2)$. 


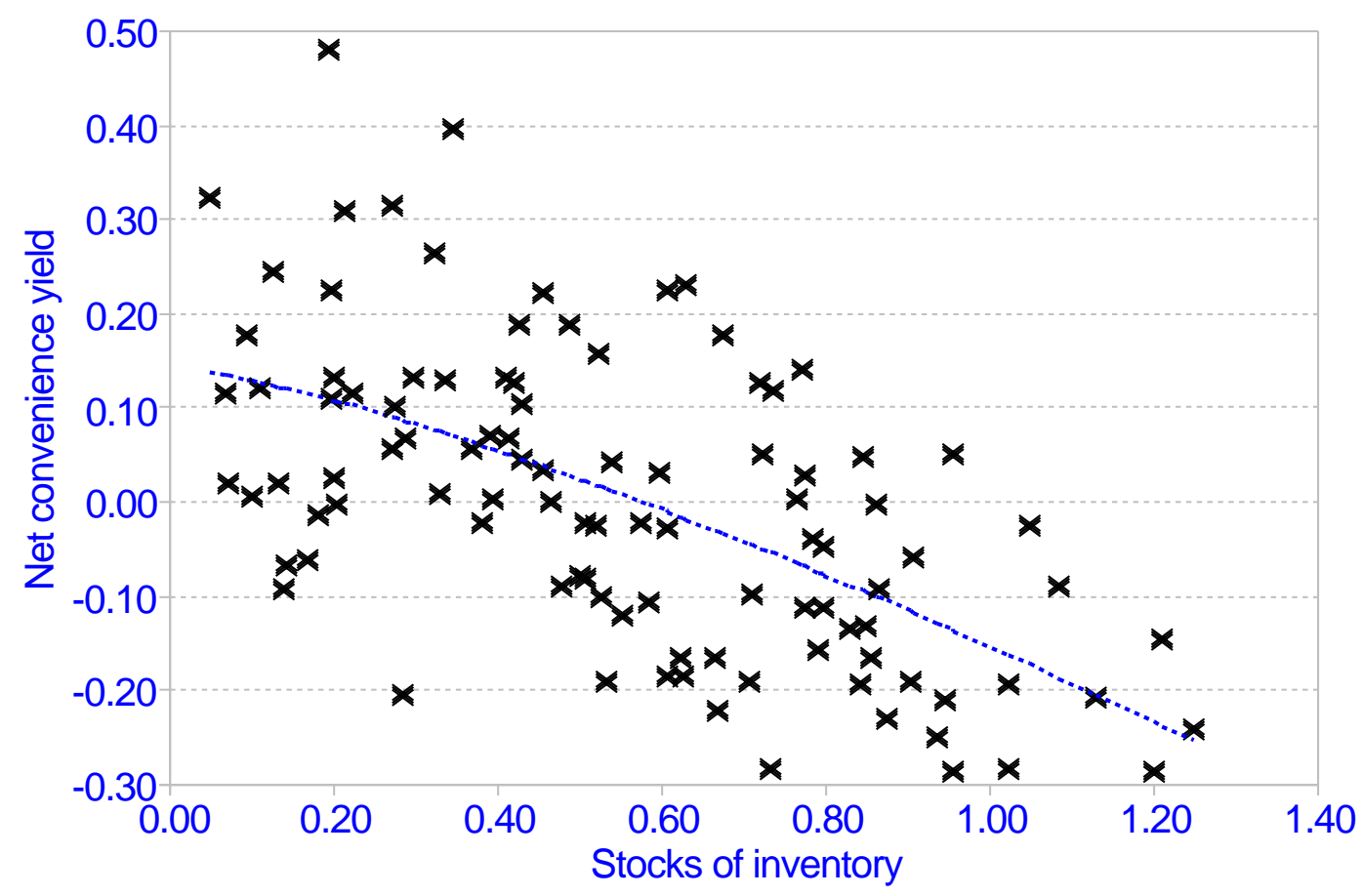

$\times$ Observations $\quad \cdots \cdots \cdot$ Regression result

Figure 6: Normalized inventories and net convenience yields for corn. The figure displays the sample of corn inventories and filtered net convenience yields and the estimated (seasonally unadjusted) relationship using the estimates in Table 5. 


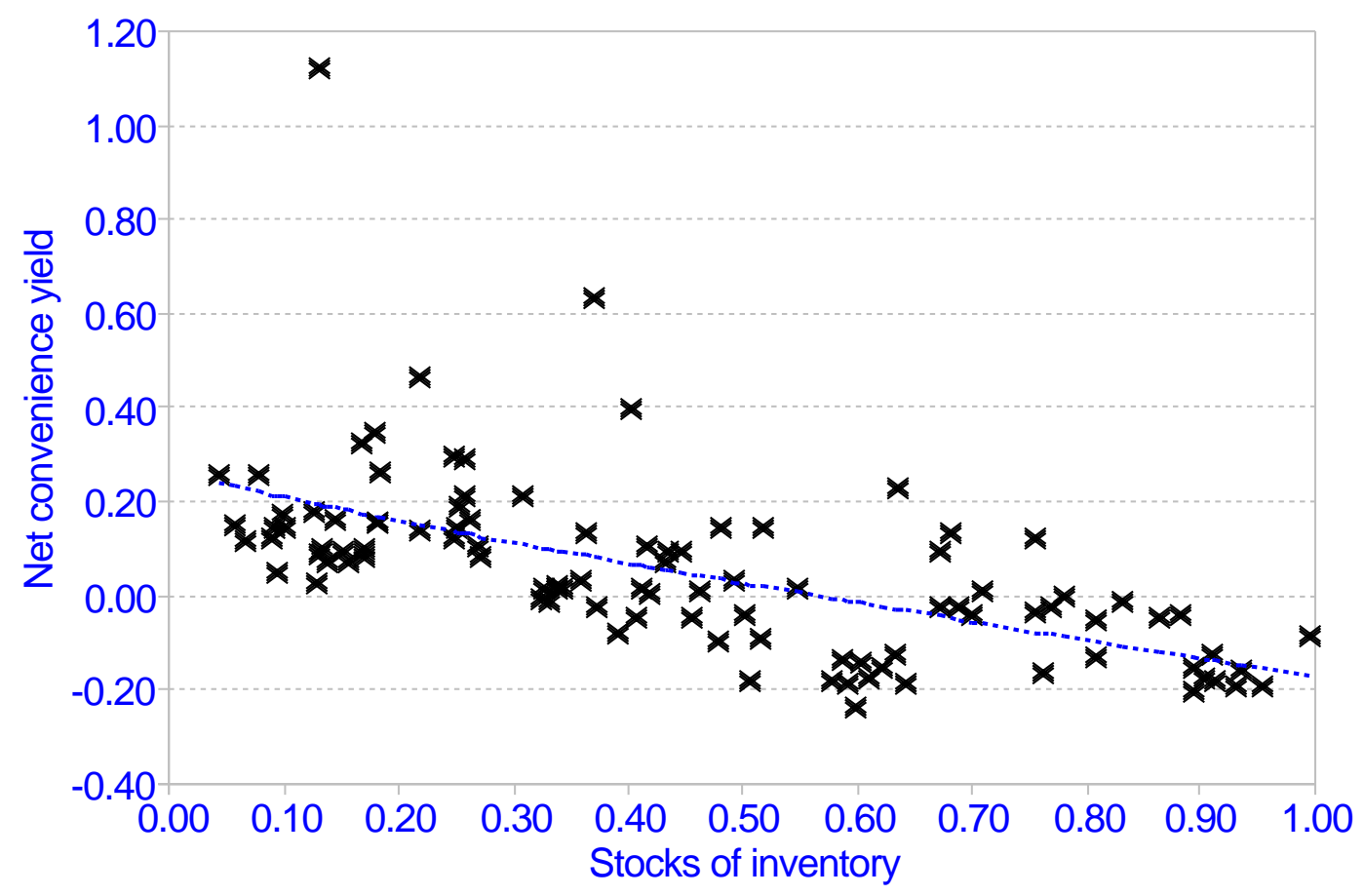

$\times$ Observations $\quad \cdots \cdots \cdot$ Regression result

Figure 7: Normalized inventories and net convenience yields for soybeans. The figure displays the sample of soybean inventories and filtered net convenience yields and the estimated (seasonally unadjusted) relationship using the estimates in Table 5. (The outlier $\left(I_{t} / Q_{t}, \delta_{t}(0.25)\right)=(0.1313,1.123)$ is recorded for June 1973.) 


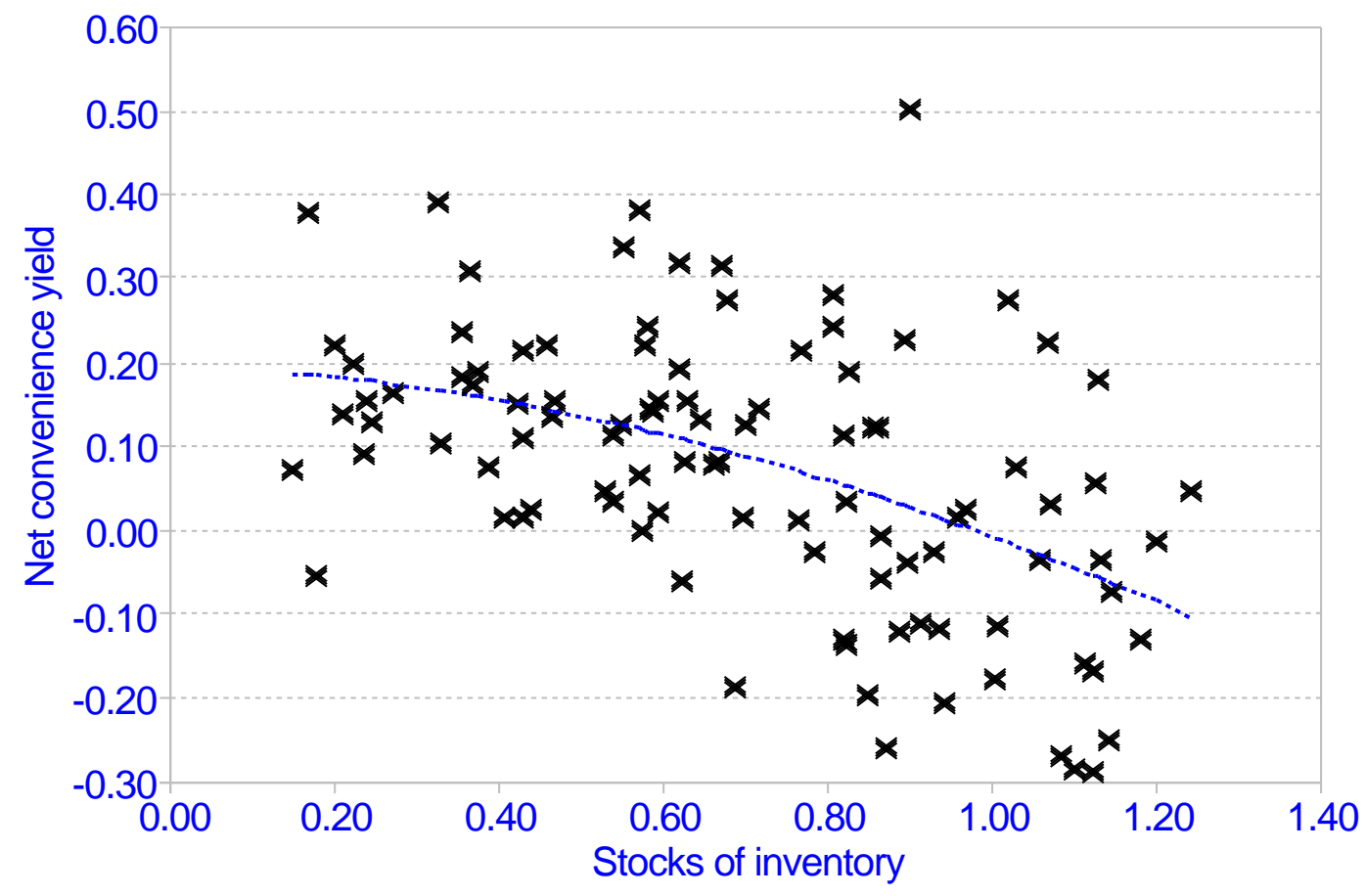

$\times$ Observations $\quad \cdots \cdots \cdot$ Regression result

Figure 8: Normalized inventories and net convenience yields for wheat. The figure displays the sample of wheat inventories and filtered net convenience yields and the estimated (seasonally unadjusted) relationship using the estimates in Table 5. 